\title{
PPP 模式的轨道交通工程项目初步设计概算评估的思考
}

\author{
陈廷模 \\ 重庆天廷工程咨询有限公司 \\ DOI:10.32629/btr.v2i8.2480
}

[摘 要] 轨道交通相对于地面交通具有容量大、速度快、准点率高等特点,在交通路网中起着越来越重要的作用,同时轨道交 通的建设对带动城市经济社会的发展起着至关重要的作用。1965年北京开始建设全国第一条地铁线路, 至今全国已有北京、 天津、上海、广州、南京、沈阳、成都、武汉、西安、重庆、深圳、苏州、杭州等城市相继开通轨道交通, 超过30座城市正 在建设、筹建或规划轨道交通线路。至2020年全国规划地铁总里程将达6100km。过去的十年是中国轨道地铁发展的黄金期, 中国的经济总量从全球的第七位上升到全球的第二位,中国轨道交通产业的发展已经走在了世界前列。随着我国经济的快速 发展和城市化进程的加快,轨道交通以其快捷、高效、环保等特点,成为国内各大城市解决交通问题的重要措施。

[关键词] PPP 模式; 轨道交通; 概算评估

轨道交通属于公益基础设施, 产生的经济效益不高, 但 投融资需求十分巨大, 单靠政府投资难以为继, 因此, 在投资 体制和模式上需要创新, 包括积极探索多元化投融资方式, 借鉴海内外的成功经验, 新时期中国轨道交通改变了计划经 济时期全部由政府投资的局面。PPP模式的实质内容就是国 家和相关政府吸引社会投资以开拓公共基础设施的建设资 金, 提高公共产品的服务效率. 轨道交通引入PPP投资模式 建设不仅可以缓解地方政府财政压力, 降低项目建设运营风 险, 同时也可拓宽社会资本投资渠道, 使得项目建设更加科 学有效。

\section{1 轨道交通工程引入 PPP 建设模式的意义}

PPP (Public Private Partnerships) 模式, 即公共部门 与社会投资人合作模式, 通过这种合作形式, 合作各方共同 承担责任和融资风险, 既满足了社会投资人盈利性的要求, 又提高了公用事业的服务效率和质量。

PPP融资方案与以往社会投资人参与公共基础设施建设 的项目融资方案相比, 虽然并不是全局上的改变, 但带来的 影响却是巨大的。具体来说, PPP融资方式具有以下优势:

$1.1 \mathrm{PPP}$ 组织机构的设置形式可以尽早确定哪些项目可 以进行项目融资, 并可以在项目的初始阶段更好地解决项目 整个生命周期中的风险分配。

$1.2 \mathrm{PPP}$ 模式中的社会投资人以实现盈利为目的, 他们 必会将最优质的服务提供给消费者, 从而赢得顾客。

1. $3 \mathrm{PPP}$ 模式可以使参与公共基础设施项目融资的社会 投资人在项目的前期就参与进来, 有利于利用社会投资人先 进的技术和管理经验。采用PPP方案, 可以使有意向参与项目 建设的社会投资人与项目所在国政府或有关机构在项目的 论证阶段共同商讨项目建设过程中所采用的技术方案, 从而 有可能采用较新的研究成果。

1. 4 通过PPP融资模式, 使得项目的参与各方重新整合, 组成战略联盟, 对协调各方不同的目标起到了关键性作用。

1.5 在PPP建设模式下, 将项目的设计、建造、营运和管
理等有效地结合起来, 并且可以及时筹集到所需的资金, 提 高项目执行的效率。

\section{2 轨道工程初步设计概算评估包括的主要内容}

轨道交通工程初步设计概算评估包括四大部分, 分别为 工程费用、工程建设其他费用、预备费及专项费用。

2.1工程费用: 工程费用分为建筑工程费、安装工程费 及设备购置费三部分。主要内容包括: 车站、区间、轨道、 通信、信号、供电、综合监控、火灾自动报警、环境与设备 监控、安防与门禁、通风、空调与采暖、给水与排水、消防、 自动售检票、站内客运设备、站台门、运营控制中心、车辆 基地、人防等。

2. 2 工程建设其他费: 分为前期工程费和其他费用两部 分。主要内容包括: 土地征用及补偿、临时占地、建 (构) 筑物 拆迁补偿、树木及绿化赔偿、道路恢复、道路破复、管线迁改、 交通疏解、场地准备、项目建设管理费、建设工程监理及相关 服务费、招标交易服务费、可行性研究费、环境影响评价费、 客流预测报告编制费、地震安全性评价费、地质灾害危险性评 估费、节能评估费、社会稳定风险评估费、防洪评价费、文物 勘探及保护费、研究试验费、勘察设计费、咨询费、引进技术 和引进设备其他费、综合联调及试运行费、专利及专有技术使 用费、生产准备及开办费、工程保险费、特殊设备安全监督检 验费、安全生产保障费、配合辅助工程费等。

2. 3预备费：包括基本预备费和价差预备费。

2.4 专项费用: 包括车辆购置费 (含车辆监造费) 、建设 期贷款利息和铺底流动资金。

\section{3 影响轨道工程初步设计概算评估投资的主要因素}

3. 1 前期工作对初步设计概算投资的影响。前期规划的 合理性、可行性研究的深入性、征地拆迁的及时性等直接影 响初步设计概算的准确性。

3.1.1制定详细周全的建设规划。轨道交通规划应纳入 并服务于城市的建设发展规划和相应的交通规划, 要与城市 地面交通配合, 还需与公路、铁路、民航等大交通协调。工 
程建设规划要充分考虑城市未来的发展和沿线土地的开发利 用, 这样既有利于建设资金的筹措, 又有利于带动城市的发展 和经济的繁荣, 同时还可以组织稳定的客流, 提高后期的运营 收入。杜绝因前期规划不合理、线路选择偏差、调研工作不 深入、规划用地控制不力等因素致使项目投资不可控。

3.1.2科学深入地开展可行性研究。可行性研究是基本 建设法定程序之一, 轨道交通项目必须进行可行性研究, 其 目的是对建设项目进行多方案技术论证和经济比较, 在满足 设计功能的前提下, 选择性价比高的最优方案, 以减少项目 决策的盲目性。可行性研究阶段的设计单位应多角度、全方 位地深入研究, 对建设规模、建设内容、建设功能和标准准 确定位, 并提出多个建设方案, 进行技术论证和经济比较后 推荐出最优方案。

3.2 初步设计文件对初步设计概算投资的影响。初步设 计是在批准的可行性研究报告的基础上, 设计单位进一步细 化后开展的设计工作。初步设计文件经上级部门审查批准后, 作为编制施工图设计文件或技术设计文件的基本文件, 批复 的概算总投资是项目投资的最高限额。因此, 初步设计概算 比可行性研究阶段的可研投资估算更深、更细、更准。初步 设计概算投资是招投标阶段的重要参考资料, 是工程实施过 程中的投资控制基础, 是财政部门进行经济效益评价的重要 依据。PPP建设模式通过招标方式选择社会资本方, 往往把批 准的概算公布给投标人, 投标人以此作为建设期投资的最高 限额。因此PPP建设模式下项目的初步设计概算投资的准确 性、全面性比普通建设项目更为重要。初步设计文件对初步 设计概算投资的影响主要有:

3.2.1初步设计时间短, 设计仓促, 基础资料尚不完善。比 如没有进行必要的初步设计勘察或勘察细度不够, 致使敷设方 式选择不合理, 造成初步设计阶段的投资与实际投资差异大。

3.2.2初步设计对于建设标准的确定不科学, 装修标准 偏高, 设备选型缺乏前瞻性, 车辆选型不合理等, 实施时产生 较多的设计变更。

3.2.3 由于前期可研投资估算不足, 为控制初步设计概 算投资不超过可研估算投资的 $10 \%$, 人为压缩初步设计概算 投资。

3.2. 4 城区施工的轨道交通工程征地拆迁工作启动晚, 项目实际施工工期延长, 费用增加。

3.2.5设备国产化程度不高, 国产化率计算方式不合理, 或者项目业主为了节约运营费用, 盲目迷信进口设备, 要求 设计人按进口设备参数指标进行设备选型, 造成投资增加。

3. 2 . 6 设计单位在初步设计阶段未深入实地调查和论证, 施工工法不合理, 比如原设计明挖的改暗挖, 原设计爆破的 改非爆或TBM盾构施工。

3.2 . 7 对于大型临时设施和特殊施工措施, 初步设计阶 段未提供或不能提供指导性施工组织设计, 初步设计概算对 措施费的计算无依据, 造成错算、漏算。

3. 2 . 8 初步设计阶段设计人员注重结构安全、技术先进,
忽视方案的经济性, 造价人员注重投资计算, 忽视技术方案 的可行性和不完整。由于技术和经济结合不紧密, 甚至严重 脱节, 造成概算投资偏离实际较大。

\section{4 轨道工程初步设计概算评估要点}

4. 1对项目基本建设程序进行评审

4.1.1概算评估阶段对基本建设程序进行评审, 包括审 核项目前期规划用地、立项手续是否完备。

4.1.2项目环评、地灾、地震、通航论证、特殊研究试 验等是否开展, 并取得了相关部门的批复。

4. 1. 3地勘资料是否齐全, 达到了初步设计深度。

4.1.4可行性研究报告、初步设计等审批程序是否合规, 并取得了批复。

4.1 .5 资金来源是否落实, 是否与可研批复一致。

4.1.6建设模式及设计、监理、社会资本方的选择是否 与可研批复一致。

4. 2 对基础资料进行评审。初步设计概算一般由各级发 改委委托有资质的专业咨询机构进行评估, 通常委托方只提 供委托书和送审概算书, 其他基础资料 (项目初步设计文件、 前期文件、已签订的合同等) 由项目业主提供。概算评估主 要审查以下基础资料:

4.2. 1 是否具备项目建议书批复、可研报告及批复、初 步设计批复等前期批复文件。

4.2. 2 是否取得环评、地灾、地震、水土保持等行业主 管部门的审批意见。

4.2. 3全面熟悉初步设计文件, 查看初步设计图纸深度 是否满足设计规范的要求, 是否满足PPP建设模式概算评估 要求。

4. 2. 4 征地拆迁工作是否已经开展, 提交的相关费用是 否完整。

4. 2.5 对于复杂的综合管网迁改项目 (电力、燃气、通信、 跨越铁路公路等), 项目业主是否提前与产权单位衔接。

4.2. 6 项目是否存在代建 (本应属于该项目的工作内容, 由于交叉不可分割等原因, 交由其他项目代建, 或者该项目 代建了其他项目部分内容)。

4.2.7已签订的前期咨询、勘测、设计、环评、地灾、 地震、水土保持等合同是否提供。

4.2.8 初步设计是否超过或削弱可研阶段明确的建设规 模、建设内容、建设功能和标准。

4.2.9 编制的初步设计概算是否超过批复可研投资的 $10 \%$ 以上。

4. 3 实施现场踏勘。在熟悉基础资料后, 应对项目现场进 行全面踏勘, 避免因未实施现场踏勘工作或现场踏勘工作深 度不够, 造成评估投资与现场不符。概算评估现场踏勘应重点 关注现场地形地貌、进场道路、水电接入点位置、现状交通、 现状建 (构)物、周边弃土渣场分布等。对于现场实际与初步 设计文件不符的, 应及时书面函告委托单位及项目业主。

比如, 某项目在做建议书和可研时, 均按照初勘的原始 
地貌计算投资, 但是由于附近的项目需借土, 在两家项目业 主的协调下, 已对本项目进行了平场, 但初步设计单位并未 将该因素纳入初步设计图纸中, 若评估概算未实施现场踏勘, 将造成评估概算投资虚高。

4. 4全面复核工程数量。轨道工程编制概算一般直接根 据设计图提供的工程数量, 并未全面复核所有工程量, 直接 由造价人员计算造价, 容易出现多计、漏计的情况。由于设 计方案的频繁调整, 甚至会出现编制概算与初步设计图纸不 匹配, 编制概算和评估概算计算的工程量出现较大误差。因 此, 概算评估特别是PPP建设模式下的概算评估, 对工程量进 行全面复核是必须进行的工作, 也是最重要的工作。工程量 复核过程中, 对于初步设计图中的差、错、漏问题, 应及时书 面函告委托方和项目业主, 请设计单位补充和修正, 纳入概 算评估中。

4.5正确采用概算定额、编制规定、指标和文件。概算 评估应根据项目的类型, 正确采用概算定额、编制规定、指 标和文件, 应注意其法定性、针对性、合理性和时效性。

4. 5. 1 根据项目的专业类型选择合适的定额体系, 目前 轨道项目中车站、区间等土建项目采用轨道概算定额中的土 建配套定额, 轨道、通信、信号、供电、综合监控、火灾自 动报警、环境与设备监控、安防与门禁、通风、空调与采暖、 给水与排水、消防、自动售检票、站内客运设备、站台门、 运营控制中心、人防等站后工程采用轨道概算定额中的安装 配套定额, 车辆基地一般采用房屋建筑概算配套定额, 轨道 专用跨江大桥一般采用市政概算配套定额。

4. 5. 2轨道工程概算评估目前采用《轨道交通工程设计 概算编制办法》（建标 [2017]89号）。

4. 5. 3 由于初步设计深度的限制, 不能出具详细初步设 计图纸的内容按类似工程指标暂列。在实施过程中, 这部分 要特别注意限额设计。

4. 5. 4 建设工程其它费用的计算需引用现行文件, 不能 采用已经停止使用的作废文件。

4. 6概算评估中特殊问题的处理

4. 6. 1 初步设计深度问题: 轨道项目线路长、体量大, 由于建设任务的紧迫性, 初步设计时间被压缩较多, 导致前 期研究深度不足、图纸较粗, 实施阶段变更多, 导致概算投资 把控难度增大。对PPP项目来说, 应尽量避免因设计深度不够 带来的投资计算偏差大, 这就要求概算评估单位认真深入地 读初步设计图纸, 梳理设计问题提交设计单位, 将设计回复 和补充文件纳入概算评估中。初步设计阶段确实不能细化的, 可采用类似项目指标估算后以暂列的方式纳入概算。

4.6.2 初步设计阶段重要设备选型问题: 一般情况下, 轨道工程设备的购置和安装占工程费用的 $40-45 \%$, 设备国 产化程度的高低对工程造价具有极大的影响。我国早期轨道 交通工程的设备多以进口为主, 造价很高。但近年来, 随着我 国科技的发展, 通信设备国内完全可以解决, 信号系统也可 由国内厂家与国外合作生产加以解决, 牵引供电, $95 \%$ 以上的
装备都能达到国产化。采用国产化设备, 可以大幅降低工程 造价, 节约运行成本, 还可以为轨道交通设备生产行业的持 续发展创造有利的条件。但是设备选型在初步设计阶段往往 还不明确, 无法准确核价, 如相关经验不足极易造成材料、设 备核价出现较大偏差。概算评估时应加强与项目业主和设计 人的沟通, 确定主要设备的档次及是否国产化, 利用已建成 类似轨道项目积累的经验, 收集完善的资料, 分析筛选后确 定价格。

4.6.3 定额套用、费用计算争议较大: 定额作为计划经 济时代的产物, 目前仍然是概算评估的主要依据, 定额套用、 费用计算准确是综合单价和总价准确的前提和基础。针对轨 道交通工程, 特别是暗挖隧道、盾构、铺轨工程等, 由于轨道 线路长, 实施条件差异大, 定额缺项多, 各单位对定额的理解 分歧较大, 涉及金额大, 协调难度大等, 给概算评估工作带来 较大困难。在行业主管部门的协调下及时解决争议, 合理确 定轨道项目概算评估投资非常重要, 另定额发布单位(部门) 应充分进行市场调研, 对原有概算定额进行及时补充和修编。

4.6. 4施工条件复杂: 对于轨道交通项目, 由于线路长、 穿过主城核心区域施工干扰大、现场施工条件受限、工期长、 技术复杂、涉及专业多, 在概算评估阶段, 应结合轨道项目实 施经验和特点, 多专业分工协作从量、价、工艺、材料价格、 指标分析等多方面进行系统把控, 保证概算投资控制在合理 范围之内。

4. 6.5 重大施工技术措施的指导方案：对于轨道交通工 程由于受周边建设环境的制约因素较多, 如非爆破施工、临 时施工通道设置、土石方转运方式、地上建筑、地下管线对 施工的影响等。在初步设计阶段设计人往往只注重结构本身 的设计, 对于施工技术措施缺乏研究, 初步设计只提供了简 单的工序图, 没有形成指导性施工方案, 对于大型临时设施 和主要的施工措施只有示意图或定性的描述, 甚至设计中任 何描述都没有, 无法比较准确地计算工程量, 从而计算投资 额。这就要求概算评估单位根据项目的特点, 提出关于重大 施工技术措施的相关问题, 书面函告委托方和项目业主, 请 设计单位完善重大施工技术措施的指导方案, 或者另行委托 有资质的第三方编制针对性重大施工技术措施的指导方案， 作为概算评估的依据, 计算相应投资。

4. 6.6 出渣方式及渣场的选择: 轨道工程土建部分以车 站、区间等地下工程为主, 土石方开挖及外弃工程量很大。 由于城市开发力度以及环保的压力, 城区施工的轨道工程出 渣方式及渣场的选择越来越难, 工程实施过程中, 出渣方式 及渣场的选择成为制约工期和投资的主要因素。

城区施工的轨道工程由于城市交通异常繁忙, 白天一般 不能出渣, 但夜间又不允许爆破, 因此土石方存在临时堆放 和二次转运。

轨道工程线路长, 由于建设工期的限制, 施工工作面会 有很多个, 地下工程往往通过施工通道、坚井等辅助设施出 渣, 明挖车站、区间通过塔吊、卷扬机等机械提升出渣。这 
些出渣措施需要在初步设计文件中明确, 提供详细的工程筹 划及相应的指导性措施方案, 概算评估时将其投资纳入。

随着城市建设的不断发展, 城市中的渣场越来越少, 建 设项目存在弃渣运距越来越远、渣场处理及管理费越来越高 的问题, 在初步设计概算评估时, 概算评估单位应充分调查 附近的渣场情况, 一般不应少于三个, 经过分析测算后确定 合理的渣场运距和渣场处理及管理费。由于目前定额套用的 土石方外运综合单价比市场价高得多, 为了合理控制投资, 评估单位与委托方和项目业主沟通后, 土石方外运综合单价 可以结合市场价计算。

4. 6. 7 特殊材料、半成品询价: 对于轨道交通工程, 由于 特殊材料、专用设备供应厂家较少, 新材料新工艺的不断更 新, 特殊材料和设备的询价成为概算评估工作的重点, 同时 也成为难点。比如轨道、道岔、疏散平台、道床吸音板、人 防门、车辆段工程车辆、车辆段工艺设备、自动扶梯及垂直 电梯、站台门、通信、监控设备等, 费用占比大, 但这些产品 生产厂家有限, 且多数为外地厂家, 概算评估阶段询价比较 困难。在市场经济条件下, 同一种型号规格的设备存在多家 厂家生产竞争, 报价不一, 使得设备材料价格相差较大。概算 评估中, 应加强与项目业主和设计单位的沟通, 收集整理已 建类似工程的资料, 结合询价结果, 确定合理的价格。

4. 7工程费用评估工作完成后, 应以工程费用为基础, 对 工程建设其它费进行评估, 包含项目业主管理费、勘察设计 费、监理费、招投标费用等内容。

4. 7. 1在评估前, 应收集梳理文件依据, 特别注意不得引 用作废文件作为计算依据。

4.7.2收集项目前期已经签订的合同, 已签订合同标准 超过文件规定的, 及时向委托方反映。

4. 7. 3 评估征地拆迁费时, 注意复核用地范围是否超出 红线。

4. 7. 4没有文件计算依据的事项不能列入概算投资, 同 时也不能漏列项目。

4. 7.5 对于不能准确计算投资的项目应按指标估算后纳 入概算暂列。

4. 8车辆购置费: 根据初步设计文件中选择的车型和车 辆数量, 计算车辆购置费。远期规划的车辆一般不纳入概算 中, 由于目前国产车辆完全能够满足设计要求, 评估概算应 按国产车辆价格计算车辆购置费。

4.9 建设期贷款利息：建设期贷款利息的计算与资金来 源、贷款比例、建设工期及当期利率有关, 应严格按规定计算。

4. 10 指标分析：概算评估所有费用计算完成后, 应形成 指标分析表进行详细的指标分析, 对评估项目的指标进行横 向和纵向比较, 判断有无异常, 若发现指标异常, 应及时分析 原因, 反查初步设计文件是否经济合理, 有无提高设计标准 的现象, 概算评估是否存在疏漏, 若存在, 应及时予以调整。
指标分析不仅是对本项目的经济合理性进行分析总结, 也为以后的轨道工程建设提供宝贵的经验数据。

4. 11评估概算与批复可研进行对比。由于轨道项目的线 路长、制约因素多、技术复杂、涉及专业多、受外界影响因 素大, 在可研评估时, 可能由于方案设计深度的不足、技术经 济资料的缺乏, 致使可研投资不足; 或者初步设计阶段对项 目规模、范围进行了扩大, 初步设计概算投资超过可研批复 投资, 甚至超过 $10 \%$ 以上。因此, 评估概算与批复可研进行对 比是必须的程序, 对比分析分两个方面:

4.11. 1 与可研方案进行对比分析: 初步设计与可行性研 究的规模、标准、功能、范围是否一致, 对不一致的地方应 阐明变化原因, 并查阅是否履行了相关的审批手续。

4.11. 2 与可研批复投资进行对比分析: 评估概算与可研 批复投资应作对应项次的比较, 若初步设计与可行性研究规 模、标准、功能、范围一致, 可直接作同口径比较, 分析费用 差异及百分比; 若初步设计与可行性研究规模、标准、功能、 范围存在差异, 应对差异部分涉及的金额进行测算, 分析费用 差异及百分比。对评估概算超出可研批复投资 $10 \%$ 以上的项目, 应及时向委托人和项目业主沟通汇报, 查明原因, 确需调整的, 重新报送可研报告和可研投资, 并经发改委审查批复。

\section{5 经批复的初步设计概算对PPP建设模式轨道工程的} 意义

对于PPP模式的建设项目, 概算总投资的合理确定与控 制事关政府和社会资本合作各方的切身利益, 经批准的初步 设计概算是测算财务模型的基础，也是制定PPP实施方案的 重要依据。因此初步设计概算投资的合理性、准确性、完整 性对政府和社会资本方都具有重要意义。

5.1轨道交通工程初步设计概算是初步设计文件的重要 组成部分, 是全面反映建设项目投资规模和投资构成的主要 文件, 应完整反映设计范围内工程项目建设全过程所需的全 部费用。

5.2 初步设计概算应符合轨道交通工程项目建设、投资 构成和工程管理的要求, 有利于合理确定和有效控制轨道交 通工程造价。对充分发挥投资效益、提高经济效益和社会效 益具有重要意义。

5.3 经批准后是编制建设项目投资计划、确定和控制投 资的依据, 是考核设计方案经济合理性和选择最佳方案的依 据, 是考核建设项目投资效果的依据。

\section{[参考文献]}

[1]王洁.PPP模式下轨道交通工程概算审核的重点与难 点 $[J]$.上海建设科技,2019,(01):82-84.

[2]李晓雁.基于PPP模式的城市轨道交通工程价款计价 方式浅析[J].黑龙江交通科技,2018,41(09):230-231.

[3]张蓝兮,彭放.城市轨道交通工程PPP模式选择及典型 案例分析 [J].施工技术,2018,47(2):75-77. 